\title{
High-grade postoperative complications affect survival outcomes of patients with colorectal Cancer peritoneal metastases treated with Cytoreductive surgery and Hyperthermic Intraperitoneal chemotherapy
}

Sicheng Zhou ${ }^{1+}$, Qiang Feng ${ }^{1+}$, Jing Zhang ${ }^{2}$, Haitao Zhou', Zheng Jiang ${ }^{1}$, Zheng Liu', Zhaoxu Zheng ${ }^{1}$, Haipeng Chen ${ }^{1}$, Zheng Wang ${ }^{1}$, Jianwei Liang ${ }^{1 *}$, Wei Pei $^{1^{*}}$, Qian Liu' ${ }^{1}$ Zhixiang Zhou ${ }^{1}$ and Xishan Wang ${ }^{1}$

\begin{abstract}
Background: This study aimed to evaluate the impact of postoperative complications on long-term survival in patients with peritoneal metastasis (PM) arising from colorectal cancer (CRC) treated with cytoreductive surgery (CRS) and hyperthermic intraperitoneal chemotherapy (HIPEC).

Methods: Patients with PM arising from CRC treated with CRS and HIPEC were systematically reviewed at the China National Cancer Center and Huanxing Cancer Hospital from June 2017 to June 2019. High-grade complications that occurred within 30 days were defined as grade 3 to 4 events according to the Common Terminology Criteria for Adverse Events (CTCAE) classification. Univariate and multivariable Cox regression models for overall survival were created. Predictors of high-grade postoperative complications were evaluated with univariate and multivariate logistic regression analyses.

Results: In all, 86 consecutive cases were included in this study. Forty-one patients (47.7\%) developed postoperative complications, while 22 patients (25.6\%) experienced high-grade complications. No mortality occurred during the postoperative period. The median survival of all patients was 25 months, and the estimated 3year overall survival (OS) rate was $35.0 \%$. In the multivariable Cox regression analysis, a high peritoneal carcinomatosis index $(\mathrm{PCl})$ score $(\mathrm{HR}, 1.07,95 \% \mathrm{Cl}, 1.01-1.14 ; \mathrm{P}=0.015)$ and grade $3-4$ postoperative complications $(\mathrm{HR}, 1.86,95 \% \mathrm{Cl}, 1.22-3.51 ; P=0.044)$ correlated with worse overall survival. High estimated blood loss (OR, 1.01, $95 \% \mathrm{Cl}, 1.01-1.02 ; P<0.001)$ was identified as an independent risk factor for developing high-grade complications.

\footnotetext{
* Correspondence: Liangjw1976@163.com; peiweifbwk@163.com ${ }^{\dagger}$ Sicheng Zhou and Qiang Feng contributed equally to this work. 'Department of Colorectal Surgery, National Cancer Center/National Clinical Research Center for Cancer/Cancer Hospital, Chinese Academy of Medical Sciences and Peking Union Medical College, Beijing 100021, China Full list of author information is available at the end of the article
}

C C The Author(s). 2021 Open Access This article is licensed under a Creative Commons Attribution 4.0 International License, which permits use, sharing, adaptation, distribution and reproduction in any medium or format, as long as you give appropriate credit to the original author(s) and the source, provide a link to the Creative Commons licence, and indicate if changes were made. The images or other third party material in this article are included in the article's Creative Commons licence, unless indicated otherwise in a credit line to the material. If material is not included in the article's Creative Commons licence and your intended use is not permitted by statutory regulation or exceeds the permitted use, you will need to obtain permission directly from the copyright holder. To view a copy of this licence, visit http://creativecommons.org/licenses/by/4.0/. The Creative Commons Public Domain Dedication waiver (http://creativecommons.org/publicdomain/zero/1.0/) applies to the data made available in this article, unless otherwise stated in a credit line to the data. 
(Continued from previous page)

Conclusion: Careful patient selection, high levels of technical skill and improved perioperative management are crucial to ensure patient survival benefits after CRS+HIPEC.

Keywords: Peritoneal metastasis, Cytoreductive surgery, Hyperthermic intraperitoneal chemotherapy, Morbidity, Prognostic factors

\section{Background}

Colorectal cancer (CRC) is the third most prevalent malignancy worldwide, with more than 1 million new cases in 2018 [1]. Peritoneal metastasis (PM) from colorectal cancer is a form of disease progression that affects approximately $10 \%$ of patients at the first surgery $[2,3]$ and is also an important reason for the poor prognosis of this disease [4]. Cytoreductive surgery (CRS) combined with hyperthermic intraperitoneal chemotherapy (HIPEC) has gradually become the standard treatment for PM arising from CRC after arduous exploration and practice [5-8]. For specifically selected patients, the median survival can reach approximately 40 months after CRS and HIPEC treatment for PM arising from CRC $[9,10]$.

Despite increasing evidence of the therapeutic efficacy of CRS+HIPEC, its safety has been doubted due to its high rates of morbidity and mortality. Recently, a large series composed of patients with varied tumour sources reported that the overall morbidity rate [11-18], severe morbidity rate $[8,13,17,19-26]$, and mortality rate $[11$, $17,19,20,27,28]$ after CRS+HIPEC were 37.9-60.5\%, $6.4-35 \%$ and $2.5-4.6 \%$, respectively. Moreover, it has been reported in the literature that the occurrence of postoperative complications after CRS+HIPEC is an independent negative prognostic factor affecting patients with PM arising from CRC [19]. Therefore, the aim of this study was to evaluate the perioperative safety and identify the risk factors for postoperative complications after CRS+HIPEC in our institution. Additionally, we sought to investigate the impact of postoperative complications on overall survival to guide future management.

\section{Methods}

\section{Patient selection}

After obtaining approval from the ethics committee of the Cancer Hospital, Chinese Academy of Medical Sciences (NCC 2017-YZ-026, Oct 17, 2017), all patients with synchronous or metachronous PM arising from CRC who underwent CRS with HIPEC were retrospectively collected between June 2017 and June 2019 at the National Cancer Center and Huanxing Cancer Hospital. The inclusion criteria included the following: (1) pathologically diagnosed malignant colorectal tumour; (2) age between 18 and 75 years; and (3) Eastern Cooperative Group (ECOG) score $\leq 1$. (4) patients performed three times complete HIPEC procedure. The exclusion criteria were as follows: (1) a previous history of other cancers; (2) patients undergoing palliative surgery, such as bypass surgery or simple ostomy; (3) peripheral blood neutrophil count $<2000 \times 10^{9} / \mathrm{L}$ or platelet count $<100 \times 10^{9} / \mathrm{L}$; (4) abnormal liver function: serum total bilirubin (TBIL) level $>21 \mu \mathrm{mol} / \mathrm{L}$ or alanine transaminase (ALT) level > $40 \mathrm{U} / \mathrm{L}$; and (5) abnormal renal function: serum creatinine level $>106 \mu \mathrm{mol} / \mathrm{L}$ or urea level $>7.1 \mathrm{mmol} / \mathrm{L}$. Finally, 86 patients met the above criteria and were included in this study. All enrolled patients in this study provided written informed consent.

\section{Perioperative management}

Patients underwent routine preoperative evaluations to assess their general condition, calculate the peritoneal carcinomatosis index (PCI), and identify distant metastasis, including laboratory examinations, abdominal contrast-enhanced computed tomography (CT), and pelvic magnetic resonance imaging. All potential $\mathrm{CRS}+$ HIPEC cases were discussed in multidisciplinary team (MDT) meetings that incorporated radiologists and medical and surgical oncologists to develop a consensus for a comprehensive treatment strategy. The PCI was used to assess the degree of PM and has scores from 0 to 3 for each of the 13 defined areas of the abdominal cavity $[29,30]$. Toxicity indexes of chemotherapy (blood, liver, and kidney toxicity), including neutrophil count, platelet count, ALT level, TBIL level, creatinine level and urea level, were measured in the morning on postoperative days (PODs)1, 3, and 5. Patients with severe liver and kidney impairment or myelosuppression will be discontinued from additional HIPEC procedure and exclude form the study.

\section{Operative details}

Depending on the location of the PM, CRS consists of various surgical and peritonectomy procedures, including pelvic peritonectomy, anterior peritonectomy, omentectomy, ovariectomy, and hysterectomy following the Sugarbaker techniques [31]. The completeness of the cytoreduction score (CC score) was recorded at the end of each operation. $\mathrm{CC}-0 / 1$ was deemed complete cytoreduction, with CC-2/3 considered incomplete cytoreduction [32]. Incomplete cytoreduction is the removal of as much as is visible to the naked eye, but there is bound to be residual tumor. Patients undergoing palliative 
surgery, such as bypass surgery or simple ostomy, are not included. All the 14 patients with liver metastasis were isolated and resectable and they underwent simultaneous resection of liver metastasis after CRS. After resection, three outflow drainage tubes and one inflow drainage tube were routinely placed in the abdomen to prepare for HIPEC. There were two chemotherapeutic regimens during HIPEC in this study. Oxaliplatin (200 $\left.\mathrm{mg} / \mathrm{m}^{2}\right)$ and raltitrexed $\left(3 \mathrm{mg} / \mathrm{m}^{2}\right)$ with or without lobaplatin $\left(50 \mathrm{mg} / \mathrm{m}^{2}\right)$ were used for intraperitoneal chemotherapy. After catheterization was completed, patients in both groups were treated with a mixed solution of chemotherapy agents and $3 \mathrm{~L}$ of saline solution in the abdominal and pelvic cavity for $60 \mathrm{~min}$ at $42-43{ }^{\circ} \mathrm{C}$. After that, four catheters remain in original position, and two more HIPEC procedures with same chemotherapeutic regimens as well as perfusion time were performed again on the second and fourth days after surgery in the ward. Two surgical specialists with more than 20 years of experience in gastrointestinal surgery performed operations at the two central, while the exactly similar HIPEC technique and postoperative treatment were performed at both centers.

\section{Postoperative complications}

Postoperative complications that occurred within 30 days were recorded and graded in accordance with the Common Terminology Criteria for Adverse Events (CTCAE) classification [33]. High-grade complications were described as grade 3 and 4 events. Leukopenia was graded as follows: grade III: < 2000-1000/mm3, and grade IV: < $1000 / \mathrm{mm} 3$. Neutropenia was graded as follows: grade III: < 1000-500/mm3, and grade IV: <500/mm3. Thrombocytopenia was graded as follows: grade III: < $50,000-25,000 / \mathrm{mm} 3$, and grade IV: $<25,000 / \mathrm{mm} 3$.

\section{Follow-up}

The postoperative systemic chemotherapy regimen was developed by two medical oncologists with expertise in the gastrointestinal field. All patients were scheduled to receive follow-up through outpatient visits or telephone interviews every 3 months for the first two years and then every 6-12 months for the next 3 years until death due to recurrence and metastasis or July 31, 2020, whichever came first. Routine examinations included CT imaging of the thorax, abdomen and pelvis and blood tests of tumour markers when appropriate. The longterm endpoint of this study was 3-year overall survival (OS).

\section{Statistical analysis}

SPSS 24.0 software (IBM, Armonk, NY, USA) was used to for statistical analysis. All results are expressed as the median with an interquartile range for continuous variables and absolute and percentage frequencies for categorical variables. Survival analysis was calculated using the Kaplan-Meier method, and data were analysed using the log rank test. All significant univariate variables were applied in the multivariate Cox regression model, and their independent prognostic value was evaluated. Univariate logistic regression models using lowgrade complications and the absence of complications as references were performed to identify independent risk factors for developing high-grade complications. Variables with $P<0.05$ in univariate analysis were included in the multivariate logistic regression model. A $P$ value < 0.05 was considered statistically significant.

\section{Results}

\section{Patient demographics and clinical characteristics}

The demographical and clinical characteristics of patients are summarized in Table 1. A total of 86 consecutive patients whose average age was $55.6 \pm 11.7$ (range, 27-74) years were included in our study, including 45 (52.3\%) male and 41 (47.7\%) female patients. Among these patients, 52 (60.5\%) exhibited synchronous PM, and $41(51.2 \%)$ underwent preoperative chemotherapy. The most common primary tumour types and histology observed were colon cancer (73.3\%) and adenocarcinoma (64.0\%), respectively. The average preoperative CEA and CA19-9 levels were 33.4 \pm 65.2 (range, 0.6-291.7) and $68.3 \pm 87.7$ (range, 0.7-363.5), respectively.

HIPEC with lobaplatin, oxaliplatin, and raltitrexed was used in $40(46.5 \%)$ cases, and HIPEC with oxaliplatin and raltitrexed was used in the remainder of the patients (53.5\%). Patients had a median PCI score of $11.2 \pm 5.7$ (range 2-24), and $62.8 \%$ of them underwent complete cytoreduction (CC score 0-1). The average operative time was $244.0 \pm 70.3$ (range, 145-510). During the operation, patients had an estimated average blood loss of $121.4 \pm 107.8 \mathrm{~mL}$ (range 20-500).

Following the operation and within 30 days, 41 patients (47.7\%) developed postoperative complications, while 22 patients $(25.6 \%)$ experienced high-grade complications (Table 2). No mortality occurred during the postoperative period. The most common complication observed was ileus $(14.0 \%, n=12)$, followed by abdominal abscess $(10.5 \%, n=9)$ and wound infection $(9.3 \%, n=8)$.

\section{Survival analyses}

The median follow-up period was 19.5 (range, 3-36) months. The median survival for all patients was 25 months, and the estimated 1-, 2- and 3-year OS rates for the entire cohort were 69.7, 50.1, and $35.0 \%$, respectively (Fig. 1). Cox univariate regression analysis identified the site of origin, PCI score, CC score, and grade 3-4 postoperative complications as factors 
Table 1 Patient demographics of 86 patients underwent CRS+HIPEC

\begin{tabular}{|c|c|}
\hline Characteristics & Total $(n=86)$ \\
\hline Age at operation ( $y$, mean \pm SD) (range) & $55.6 \pm 11.7(27-74)$ \\
\hline \multicolumn{2}{|l|}{ Gender (\%) } \\
\hline Male & $45(52.3)$ \\
\hline Female & $41(47.7)$ \\
\hline Preoperative chemotherapy (\%) & $41(51.2)$ \\
\hline \multicolumn{2}{|l|}{ Presentation of PM (\%) } \\
\hline Synchronous & $52(60.5)$ \\
\hline Metachronous & $34(39.5)$ \\
\hline \multicolumn{2}{|l|}{ Site of original (\%) } \\
\hline Colon & $63(73.3)$ \\
\hline Rectum & $23(26.7)$ \\
\hline Preoperative CEA level (ng, mean \pm SD) (range) & $33.4 \pm 65.2(0.6-291.7)$ \\
\hline $\begin{array}{l}\text { Preoperative CA19-9 level (ng, mean } \pm \text { SD) } \\
\text { (range) }\end{array}$ & $68.3 \pm 87.7(0.7-363.5)$ \\
\hline \multicolumn{2}{|l|}{ Histology (\%) } \\
\hline Adenocarcinoma & $55(64.0)$ \\
\hline Mucinous & $31(36.0)$ \\
\hline Liver metastases & $17(19.8)$ \\
\hline HIPEC regimen & $5(6.6)$ \\
\hline Lobaplatin+Oxaliplatin+Raltitrexed & $40(46.5)$ \\
\hline Oxaliplatin+Raltitrexed & $46(53.5)$ \\
\hline $\mathrm{PCl}$ score & $11.2 \pm 5.7(2-24)$ \\
\hline Operation time (min, mean \pm SD) (range) & $264.0 \pm 70.3(145-510)$ \\
\hline Estimated blood loss (ml, mean \pm SD) (range) & $121.4 \pm 107.8(20-500)$ \\
\hline Presence of ascites & $37(43.0)$ \\
\hline \multicolumn{2}{|l|}{ CC score } \\
\hline CC $0-1$ & $54(62.8)$ \\
\hline CC $2-3$ & $32(37.2)$ \\
\hline Postoperative Complications (grade 1-4) (\%) & $41(47.7)$ \\
\hline Postoperative Complications (grade 3-4) (\%) & $22(25.6)$ \\
\hline Mortality (\%) & $0(0)$ \\
\hline Total hospital stay (day, mean \pm SD) (range) & $15.4 \pm 6.0(7-44)$ \\
\hline
\end{tabular}

associated with OS (Table 3). It is noteworthy that that the prognosis of patients with mucinous adenocarcinoma was worse than that of patients with nonmucinous adenocarcinoma, however, there was no statistical difference $(P=0.096)$. In the multivariable Cox regression analysis, two variables emerged as independent prognostic factors: PCI score and grade 34 postoperative complications. Patients with high PCI scores (HR, 1.07, 95\% CI, 1.01-1.14; $P=0.015)$ and grade $3-4$ postoperative complications (HR, 1.86, 95\% CI, $1.22-3.51 ; P=0.044)$ had significantly worse overall survival (Table 3 ).
Factors for the development of high-grade complications Factors associated with high-grade complications were determined with multinomial logistic regression and are summarized in Table 4. Univariate analysis showed that high estimated blood loss $(P<0.001)$ and high PCI score $(P=0.008)$ were associated with an increased possibility of high-grade complications. However, other factors, including age, sex, American Society of Anesthesiologists (ASA) score, body mass index (BMI), preoperative chemotherapy, site of origin, liver metastases, HIPEC regimen, operative time, presence of ascites, and $\mathrm{CC}$ score, were not significantly associated with high-grade complications. Multivariate analysis showed that high estimated blood loss (OR, 1.41, 95\% CI, 1.13-1.82; $P<$ 0.001 ) was identified as an independent risk factor for developing high-grade complications.

\section{Discussion}

Great progress in the treatment of PM from colorectal cancer has been made in recent years. The peritoneal surface is usually a common site of tumour dissemination from CRC, and an increasing number of studies support surgical CRS+HIPEC as a standard treatment option for PM [5-8]. Our findings demonstrate an overall median survival of 25 months and a 3-year survival rate of $35.0 \%$ for the entire cohort; these results are inferior to previous reports in the literature [19-23]. This may be due to the high proportion $(37.2 \%)$ of patients who underwent incomplete cytoreduction and the presence of liver metastasis in $18.2 \%$ of patients in the present study.

It is essential to determine the selection factors that predict survival in PM patients undergoing this complex and potentially life-threatening procedure. However, given the lack of high-quality randomized data, the transition of CRS+HIPEC from experimental therapy to a standard treatment mode is still in progress. Until now, lessons learned from large-scale multi-institutional registry studies were that high PCI score, incomplete cytoreduction and severe carcinomatosis were associated with poor survival, even after CRS+HIPEC [27, 28]. Furthermore, Faron et al. [11] documented a linear correlation between PCI and overall survival. Woeste et al. [16] also found that both the preoperative PCI score and preoperative response to chemotherapy, together with the postoperative PCI score, were independent prognostic factors for overall survival. The present study confirmed that patients with high PCI scores had significantly worse overall survival (HR, 1.07, 95\% CI, 1.01-1.14; $P=$ $0.015)$, which is similar to the above reports.

More attention has been given to the morbidity and mortality associated with the CRS+HIPEC procedure than to its efficacy. A recent systematic review by Chua et al. showed a morbidity range from 12 to $52 \%$ and a 
Table 2 Postoperative complications of 86 patients after CRS+HIPEC

\begin{tabular}{|c|c|c|c|c|c|c|}
\hline \multirow[t]{2}{*}{ Complications } & \multicolumn{2}{|c|}{ Grade 1-2 complications } & \multicolumn{2}{|c|}{ Grade 3-4 complications } & \multicolumn{2}{|c|}{ All complications } \\
\hline & $n$ & $\%$ & $\mathrm{n}$ & $\%$ & $n$ & $\%$ \\
\hline Total & 19 & 22.1 & 22 & 25.6 & 41 & 47.7 \\
\hline \multicolumn{7}{|l|}{ Blood disorders (grade 3-4) } \\
\hline Leukopenia & 2 & 2.3 & 0 & 0 & 2 & 2.3 \\
\hline Neutropenia & 2 & 2.3 & 0 & 0 & 2 & 2.3 \\
\hline Thrombocytopenia & 5 & 5.8 & 0 & 0 & 5 & 5.8 \\
\hline \multicolumn{7}{|l|}{ Cardiac disorders } \\
\hline Arrhythmia & 4 & 4.7 & 1 & 1.2 & 5 & 5.8 \\
\hline \multicolumn{7}{|l|}{ Respiratory disorder } \\
\hline Pneumonia & 4 & 4.7 & 2 & 2.3 & 6 & 7.0 \\
\hline Pleural efusion & 2 & 2.3 & 2 & 2.3 & 4 & 4.6 \\
\hline \multicolumn{7}{|l|}{ Gastrointestinal disorders } \\
\hline Anastomotic leakage & 3 & 3.5 & 3 & 3.5 & 6 & 7.0 \\
\hline lleus & 6 & 7.0 & 6 & 7.0 & 12 & 14.0 \\
\hline Gastrointestinal hemorrhage & 2 & 2.3 & 2 & 2.3 & 4 & 4.7 \\
\hline \multicolumn{7}{|l|}{ Renal and urinary disorders } \\
\hline Urinary infection & 2 & 2.3 & 0 & 0 & 2 & 2.3 \\
\hline Renal failure & 0 & 0 & 1 & 1.2 & 1 & 1.2 \\
\hline Urinary retention & 0 & 0 & 2 & 2.3 & 2 & 2.3 \\
\hline \multicolumn{7}{|l|}{ Other disorders } \\
\hline Abdominal abscess & 3 & 3.5 & 6 & 7.0 & 9 & 10.5 \\
\hline Rectovaginal fistula & 0 & 0 & 1 & 1.2 & 1 & 1.2 \\
\hline Intra-abdominal hemorrhage & 1 & 1.2 & 3 & 3.5 & 4 & 4.7 \\
\hline Wound infection & 5 & 5.8 & 3 & 3.5 & 8 & 9.3 \\
\hline
\end{tabular}

mortality range of $0.9-5.8 \%$ in 10 specified international treatment centres that were regarded as high-volume and experienced centres [34]. Our institution demonstrated that the overall morbidity rate, severe morbidity rate, and mortality rate after CRS+HIPEC were 47.7, $25.6 \%$ and 0 , respectively, which is basically consistent

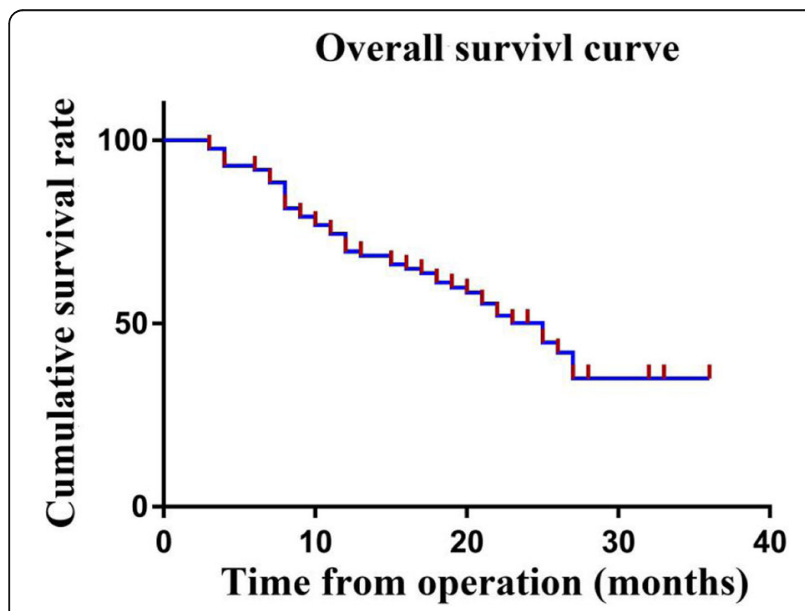

Fig. 1 Overall survival rate of 86 patients after CRS+HIPEC with the results reported by international centres. The perioperative results reported by various institutions are quite different, which may be due to differences in diagnosis and treatment experience and cytoreductive techniques in various regions around the world. Furthermore, this difference is also attributed to the lack of unified standards for treatment parameters such as dose, temperature, perfusion time, and chemotherapy regimen in various institutions.

In addition, the present study showed that patients with high-grade complications had a worse prognosis than those without complications (HR, 1.86, 95\% CI, $1.22-3.51 ; P=0.044)$. The most frequent complication observed in our patient cohort was ileus (14.0\%), followed by abdominal abscess (10.5\%). Tan et al. reported that patients without complications had significantly better survival than those with high-grade complications (HR, 0.35, 95\% CI, 0.15-0.81; $P<0.001$ ) [35]. A meta-analysis study including 717 patients who underwent CRS+HIPEC conducted by Narasimha et al. also showed that the presence of grade III/IV morbidity was independently associated with worse overall survival (HR, 1.59, 95\% CI, 1.17-2.16; $P=0.003$ ) [36]. The above 
Table 3 Univariate and multivariate Cox regression analysis of overall survival in 86 patients after CRS+HIPEC

\begin{tabular}{|c|c|c|c|c|}
\hline \multirow[t]{3}{*}{ Variables } & \multicolumn{4}{|l|}{ Overall survival } \\
\hline & \multicolumn{2}{|c|}{ Univariate analysis } & \multicolumn{2}{|c|}{ Multivariate analysis } \\
\hline & $\mathrm{HR}(95 \% \mathrm{Cl})$ & $P$ & $\mathrm{HR}(95 \% \mathrm{Cl})$ & $P$ \\
\hline Gender: male/female & $1.21(0.68-2.18)$ & 0.517 & & \\
\hline Age at operation & $1.01(0.99-1.04)$ & 0.400 & & \\
\hline Preoperative chemotherapy (no/yes) & $0.79(0.40-1.55)$ & 0.489 & & \\
\hline Synchronous/metachronous & $0.80(0.44-1.47)$ & 0.476 & & \\
\hline Site of original (colon/rectum) & $2.13(1.16-3.92)$ & 0.015 & $1.71(0.913-3.20)$ & 0.094 \\
\hline Histology (adenocarcinoma/mucinous) & $1.65(0.92-3.00)$ & 0.096 & & \\
\hline Preoperative CEA level & $1.00(0.99-1.01)$ & 0.161 & & \\
\hline Preoperative CA19-9 level & $1.00(0.99-1.01)$ & 0.342 & & \\
\hline Liver metastases (no/yes) & $1.36(0.67-2.74)$ & 0.397 & & \\
\hline HIPEC regimen (lobaplatin/non-lobaplatin) & $1.60(0.87-2.95)$ & 0.134 & & \\
\hline Presence of ascites (no/yes) & $1.34(0.74-2.40)$ & 0.335 & & \\
\hline $\mathrm{PCl}$ score & $1.01(1.05-1.15)$ & $<0.001$ & $1.07(1.01-1.14)$ & 0.015 \\
\hline CC score $(0-1 / 2-3)$ & $3.36(1.85-6.08)$ & $<0.001$ & $1.92(0.96-3.83)$ & 0.064 \\
\hline Grade 3-4 Postoperative complication (no/yes) & $2.71(1.48-4.94)$ & 0.001 & $1.86(1.22-3.51)$ & 0.044 \\
\hline Leukopenia (no/yes) & $1.31(0.61-2.83)$ & 0.487 & & \\
\hline Neutropenia (no/yes) & $1.31(0.47-3.70)$ & 0.605 & & \\
\hline Thrombocytopenia (no/yes) & $1.45(0.80-2.66)$ & 0.224 & & \\
\hline
\end{tabular}

research supports our results. The occurrence of severe complications may worsen general conditions and hamper subsequent adjuvant therapies or treatment for recurrence. Therefore, improving surgical techniques and selecting suitable patients are crucial to exploiting all the benefits of this treatment strategy. The learning curve of this complex surgical procedure requires rigorous training, and a recent study suggested that surgical complications could be reduced as experience increased within an acceptable range [19].

Table 4 Predictive factors of 3-4 grade postoperative complications assessed by univariate and multivariate logistic regression analyses

\begin{tabular}{|c|c|c|c|c|}
\hline \multirow[t]{3}{*}{ Variables } & \multicolumn{4}{|c|}{ Grade 3-4 postoperative complications } \\
\hline & \multicolumn{2}{|c|}{ Univariate analysis } & \multicolumn{2}{|c|}{ Multivariate analysis } \\
\hline & $\mathrm{OR}(95 \% \mathrm{Cl})$ & $P$ & OR(95\%Cl) & $P$ \\
\hline Gender: male/female & $1.45(0.55-3.83)$ & 0.456 & & \\
\hline Age at operation & $1.02(0.98-1.07)$ & 0.347 & & \\
\hline ASA score (I-II/III-IV) & $1.47(0.48-4.50)$ & 0.499 & & \\
\hline Body mass index & $1.08(0.90-1.28)$ & 0.342 & & \\
\hline Preoperative chemotherapy (no/yes) & $1.76(0.52-5.92)$ & 0.360 & & \\
\hline Site of original (colon/rectum) & $2.47(0.88-7.0)$ & 0.087 & & \\
\hline Liver metastases (no/yes) & $1.28(0.40-4.14)$ & 0.687 & & \\
\hline HIPEC regimen (lobaplatin/non-lobaplatin) & $0.48(0.17-1.40)$ & 0.177 & & \\
\hline Operative time & $1.01(0.99-1.01)$ & 0.164 & & \\
\hline Estimated blood loss & $1.62(1.21-2.04)$ & $<0.001$ & $1.41(1.13-1.82)$ & $<0.001$ \\
\hline Presence of ascites (no/yes) & $1.14(0.43-3.03)$ & 0.790 & & \\
\hline $\mathrm{PCl}$ score & $1.12(1.03-1.20)$ & 0.008 & $1.22(0.95-1.44)$ & 0.085 \\
\hline CC score $(0-1 / 2-3)$ & $0.76(0.28-2.05)$ & 0.582 & & \\
\hline
\end{tabular}


The present study also assessed independent risk factors for the development of high-grade complications in patients undergoing CRS/HIPEC. Patients with high intraoperative blood loss were more likely to develop highgrade complications (HR, 1.41, 95\% CI, 1.13-1.82, $P<$ 0.001 ), probably because operative blood loss can reflect the complexity of the operation and the surgical risk. Therefore, preoperative imaging examinations and laparoscopic surgical exploration that can identify extensive disease and complex cytoreduction are necessary to assess the surgical risk. Likewise, Tan et al. demonstrated that under the premise of adjusting a multitude of factors, intraoperative blood loss remained associated with the development of complications [35]. Similarly, Macri et al. proved that the number of blood transfusions was an independent risk factor for severe postoperative complications [37]. Therefore, for patients with high operative risks and poor surgical tolerance, CRS+HIPEC needs to be performed prudently, and other adjuvant therapies that can replace this complex procedure can be tried.

The most significant limitation of our study is its retrospective nature, and only 86 patients were included, which may have caused some inherent selection bias. However, all therapeutic schedules of these patients were made by a multidisciplinary team specializing in colorectal cancer in our institution, and all included patient data were unabridged and reliable. Therefore, we believe that the results are reliable. Multicentre, large-scale, prospective studies are worth looking into to verify our results.

\section{Conclusion}

On the basis of our retrospective analysis, the long-term survival outcomes were influenced by high PCI scores and high-grade postoperative complications after CRS+ HIPEC in patients with PM of a CRC origin. In addition, intraoperative blood loss was an independent risk factor for the development of grade 3-4 postoperative complications. Careful patient selection, high levels of technical skill and improved perioperative management are crucial to ensure patient survival benefits after CRS+HIPEC.

\section{Abbreviations}

PM: Peritoneal metastasis; CRC: Colorectal cancer; CRS: Cytoreductive surgery; HIPEC: Hyperthermic intraperitoneal chemotherapy; CTCAE: Common Terminology Criteria for Adverse Events; ECOG: Eastern Cooperative Group; TBIL: Total bilirubin; ALT: Alanine transaminase; PCl: Peritoneal carcinomatosis index; CT: Computed tomography; MDT: Multidisciplinary team; CC score: Completeness of the cytoreduction score; OS: Overall survival

\section{Acknowledgements}

Not applicable.

Consent to publish

Not Applicable.

\section{Authors' contributions}

Contributions: (I) conception and design: JWL, SCZ, QF, and WP; (II) administrative support: JWL, ZXZ1; (III) provision of study materials or patients: JZ, QL, ZXZ2, and ZL; (IV) collection and assembly of data: HTZ and Zj; (V) data analysis and interpretation: HPC, ZW, and XSW. The authors read and approved the final manuscript.

\section{Funding}

This work was supported by the Capital' s Funds for Health Improvement and Research (2016-2-4022) and A prospective randomized controlled clinical trial of intraoperative intraperitoneal chemotherapy with raltitrexed for the prevention of peritoneal metastases from colorectal cancer in high risk patients (2020-044-KF). The funders had no role in the design of the study, data collection, analysis, and manuscript writing.

\section{Availability of data and materials}

The datasets generated and/or analysed during the current study are not publicly available due to the data is confidential patient data but are available from the corresponding author on reasonable request.

\section{Ethics approval and consent to participate}

The ethics committee of the National Cancer Center/Cancer Hospital, Chinese Academy of Medical Sciences and Peking Union Medical College approved this study. Prior written informed consent was obtained from all study participants.

\section{Competing interests}

The authors declare that they have no competing interests.

\section{Author details}

${ }^{1}$ Department of Colorectal Surgery, National Cancer Center/National Clinical Research Center for Cancer/Cancer Hospital, Chinese Academy of Medical Sciences and Peking Union Medical College, Beijing 100021, China.

${ }^{2}$ Department of Abdominal Surgery, Huanxing Cancer Hospital, Beijing 100122, China

Received: 1 October 2020 Accepted: 21 December 2020 Published online: 07 January 2021

\section{References}

1. Bray F, Ferlay J, Soerjomataram I, et al. Global cancer statistics 2018: GLOBOCAN estimates of incidence and mortality worldwide for 36 cancers in 185 countries. CA Cancer J Clin. 2018;68(6):394-424.

2. Segelman J, Granath F, Holm T, et al. Incidence, prevalence and risk factors for peritoneal carcinomatosis from colorectal cancer. Br J Surg. 2012;99(5): 699-705.

3. Lemmens VE, Klaver YL, Verwaal VJ, et al. Predictors and survival of synchronous peritoneal carcinomatosis of colorectal origin: a populationbased study. Int J Cancer. 2011;128(11):2717-25.

4. Van der Speeten K, Stuart OA, Sugarbaker PH. Pharmacokinetics and pharmacodynamics of perioperative cancer chemotherapy in peritoneal surface malignancy. Cancer J. 2009;15(3):216-24.

5. Bushati M, Rovers KP, Sommariva A, et al. The current practice of cytoreductive surgery and HIPEC for colorectal peritoneal metastases: results of a worldwide web-based survey of the peritoneal surface oncology group international (PSOGI). Eur J Surg Oncol. 2018;44(12):1942-8.

6. Cashin PH, Mahteme $\mathrm{H}$, Spång N, et al. Cytoreductive surgery and intraperitoneal chemotherapy versus systemic chemotherapy for colorectal peritoneal metastases: a randomised trial. Eur J Cancer. 2016;53:155-62.

7. Van Driel WJ, Koole SN, Sikorska K, et al. Hyperthermic Intraperitoneal chemotherapy in ovarian Cancer. N Engl J Med. 2018:378(3):230-40.

8. Klaver CEL, Wisselink DD, Punt CJA, et al. Adjuvant hyperthermic intraperitoneal chemotherapy in patients with locally advanced colon cancer (COLOPEC): a multicentre, open-label, randomised trial. Lancet Gastroenterol Hepatol. 2019;4(10):761-70.

9. Goéré $D$, Malka D, Tzanis $D$, et al. Is there a possibility of a cure in patients with colorectal peritoneal carcinomatosis amenable to complete cytoreductive surgery and intraperitoneal chemotherapy? Ann Surg. 2013. 257(6):1065-71. 
10. Quenet F, Elias D, Roca L, et al. A UNICANCER phase III trial of hyperthermic intra-peritoneal chemotherapy (HIPEC) for colorectal peritoneal carcinomatosis (PC): PRODIGE 7. J Clin Oncol. 2018;36:18.

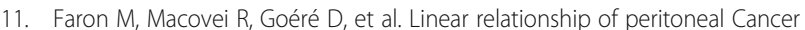
index and survival in patients with peritoneal metastases from colorectal Cancer. Ann Surg Oncol. 2016;23(1):114-9.

12. Lorimier $\mathrm{G}$, Linot $\mathrm{B}$, Paillocher $\mathrm{N}$, et al. Curative cytoreductive surgery followed by hyperthermic intraperitoneal chemotherapy in patients with peritoneal carcinomatosis and synchronous resectable liver metastases arising from colorectal cancer. Eur J Surg Oncol. 2017;43(1):150-8.

13. Sluiter NR, Rovers KP, Salhi Y, et al. Metachronous peritoneal metastases after adjuvant chemotherapy are associated with poor outcome after Cytoreduction and HIPEC. Ann Surg Oncol. 2018;25(8):2347-56.

14. Sipok A, Sardi A, Nieroda C, et al. Comparison of survival in patients with isolated peritoneal Carcinomatosis from colorectal Cancer treated with Cytoreduction and Melphalan or Mitomycin-C as Hyperthermic Intraperitoneal chemotherapy agent. Int J Surg Oncol. 2018;2018:1920276.

15. Agalar C, Sokmen S, Arslan C, et al. The impact of sarcopenia on morbidity and long-term survival among patients with peritoneal metastases of colorectal origin treated with cytoreductive surgery and hyperthermic intraperitoneal chemotherapy: a 10-year longitudinal analysis of a singlecenter experience. Tech Coloproctol. 2020;24(4):301-8.

16. Woeste MR, Philips P, Egger ME, et al. Optimal perfusion chemotherapy: A prospective comparison of mitomycin $C$ and oxaliplatin for hyperthermic intraperitoneal chemotherapy in metastatic colon cancer. J Surg Oncol, 2020, [published online ahead of print, 2020 Apr 1].

17. Beal EW, Suarez-Kelly LP, Kimbrough CW, et al. Impact of Neoadjuvant chemotherapy on the outcomes of Cytoreductive surgery and Hyperthermic Intraperitoneal chemotherapy for colorectal peritoneal metastases: a multi-institutional retrospective review. J Clin Med. 2020;9(3): 748.

18. Wong JSM, Tan GHC, Chia CS, et al. The importance of synchronicity in the management of colorectal peritoneal metastases with cytoreductive surgery and hyperthermic intraperitoneal chemotherapy. World J Surg Oncol. 2020; 18(1):10.

19. Baratti D, Kusamura S, lusco D, et al. Postoperative complications after cytoreductive surgery and hyperthermic intraperitoneal chemotherapy affect long-term outcome of patients with peritoneal metastases from colorectal cancer: a two-center study of 101 patients. Dis Colon Rectum. 2014;57(7):858-68.

20. Maillet M, Glehen O, Lambert J, et al. Early postoperative chemotherapy after complete Cytoreduction and Hyperthermic Intraperitoneal chemotherapy for isolated peritoneal Carcinomatosis of Colon Cancer: a multicenter study. Ann. Surg Oncol. 2016;23(3):863-9.

21. Froysnes IS, Larsen SG, Spasojevic M, et al. Complete cytoreductive surgery and hyperthermic intraperitoneal chemotherapy for colorectal peritoneal metastasis in Norway: prognostic factors and oncologic outcome in a national patient cohort. J Surg Oncol. 2016;114(2):222-7.

22. Massalou D, Benizri $E_{1}$ Chevallier $A$, et al. Peritoneal carcinomatosis of colorectal cancer: novel clinical and molecular outcomes. Am J Surg. 2017; 213(2):377.

23. Lee $L$, Alie-Cusson F, Dubé $P$, et al. Postoperative complications affect longterm outcomes after cytoreductive surgery and hyperthermic intraperitoneal chemotherapy for colorectal peritoneal carcinomatosis. J Surg Oncol. 2017;116(2):236-43.

24. Kozman MA, Fisher OM, Rebolledo BJ, et al. CEA to peritoneal carcinomatosis index $(\mathrm{PCl})$ ratio is prognostic in patients with colorectal cancer peritoneal carcinomatosis undergoing cytoreduction surgery and intraperitoneal chemotherapy: a retrospective cohort study. J Surg Oncol. 2018;117(4):725-6.

25. Tonello M, Ortega-Perez G, Alonso-Casado O, et al. Peritoneal carcinomatosis arising from rectal or colonic adenocarcinoma treated with cytoreductive surgery (CRS) hyperthermic intraperitoneal chemotherapy (HIPEC): two different diseases. Clin Transl Oncol. 2018;20(10):1268-73.

26. Solaini L, D'Acapito F, Passardi A, et al. Cytoreduction plus hyperthermic intraperitoneal chemotherapy for peritoneal carcinomatosis in colorectal cancer patients: a single-center cohort study[J]. World J Surg Oncol. 2019; 17(1):58.

27. Glehen O, Kwiatkowski F, Sugarbaker PH, et al. Cytoreductive surgery combined with perioperative intraperitoneal chemotherapy for the management of peritoneal carcinomatosis from colorectal cancer: a multiinstitutional study. J Clin Oncol. 2004;22(16):3284-92.

28. Elias D, Gilly F, Boutitie F, et al. Peritoneal colorectal carcinomatosis treated with surgery and perioperative intraperitoneal chemotherapy: retrospective analysis of 523 patients from a multicentric French study. J Clin Oncol. 2010; 28(1):63-8.

29. Jacquet $\mathrm{P}$, Sugarbaker $\mathrm{PH}$. Clinical research methodologies in diagnosis and staging of patients with peritoneal carcinomatosis. Cancer Treat Res. 1996; 82:359-74.

30. Elias D, Blot F, El Otmany A, et al. Curative treatment of peritoneal carcinomatosis arising from colorectal cancer by complete resection and intraperitoneal chemotherapy. Cancer. 2001;92(1):71-6.

31. Sugarbaker PH. Peritonectomy procedures. Ann Surg. 1995;221(1):29-42.

32. Koh JL, Yan TD, Glenn D, et al. Evaluation of preoperative computed tomography in estimating peritoneal cancer index in colorectal peritoneal carcinomatosis. Ann Surg Oncol. 2009;16(2):327-33.

33. Hamashige $\mathrm{S}$, Arquilla ER. Common terminology criteria for adverse events v3.0 (CTCAE). Principles and Practice of Clinical Trial Medicine. 2008;42(4): 461-533.

34. Chua TC, Yan TD, Saxena A, Morris DL. Should the treatment of peritoneal carcinomatosis by cytoreductive surgery and hyperthermic intraperitoneal chemotherapy still be regarded as a highly morbid procedure? A systematic review of morbidity and mortality. Ann Surg. 2009;249(6):900-7.

35. Tan JW, Tan GHC, Ng WY, et al. High-grade complication is associated with poor overall survival after cytoreductive surgery and hyperthermic intraperitoneal chemotherapy. Int J Clin Oncol. 2020;25(5):984-94.

36. Narasimhan $\mathrm{V}$, Tan $\mathrm{S}$, Kong J, et al. Prognostic factors influencing survival in patients undergoing cytoreductive surgery with hyperthermic intraperitoneal chemotherapy for isolated colorectal peritoneal metastases: a systematic review and meta-analysis. Colorectal Dis. 2020;22(11):1482-95.

37. Macrì A, Arcoraci V, Belgrano V, et al. Short-term outcome of cytoreductive surgery and hyperthermic intraperitoneal chemotherapy used as treatment of Colo-rectal carcinomatosis: a multicentric study. Updat Surg. 2020;72(1): $163-70$

\section{Publisher's Note}

Springer Nature remains neutral with regard to jurisdictional claims in published maps and institutional affiliations.
Ready to submit your research? Choose BMC and benefit from:

- fast, convenient online submission

- thorough peer review by experienced researchers in your field

- rapid publication on acceptance

- support for research data, including large and complex data types

- gold Open Access which fosters wider collaboration and increased citations

- maximum visibility for your research: over $100 \mathrm{M}$ website views per year

At $\mathrm{BMC}$, research is always in progress.

Learn more biomedcentral.com/submissions 